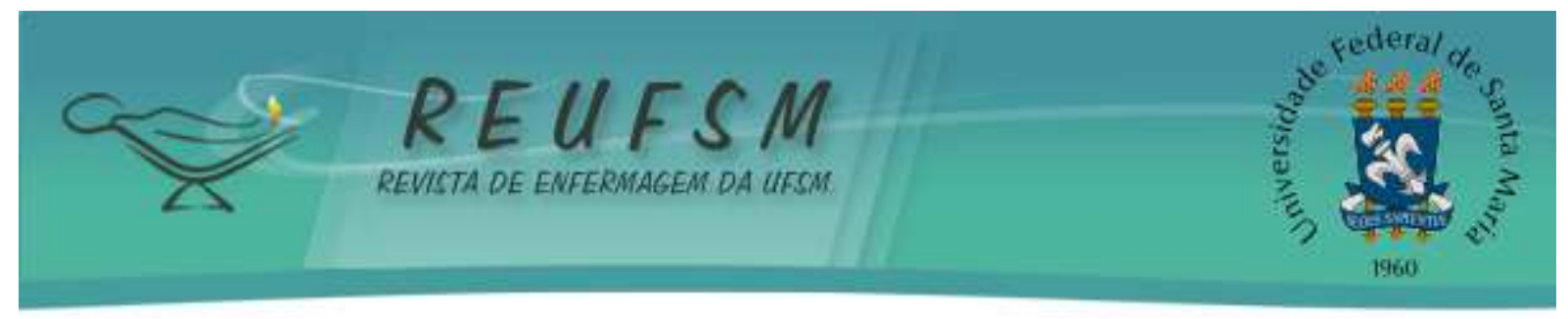

\title{
CUIDADO DE ENFERMAGEM ÀS MÃES/CUIDADORAS DE CRIANÇAS/ADOLESCENTES COM NECESSIDADES ESPECIAIS: TERAPIAS COMPLEMENTARES E ATIVIDADES LÚDICAS
}
NURSING CARE TO MOTHERS/CAREGIVERS OF CHILDREN/ADOLESCENTS WITH SPECIAL NEEDS: COMPLEMENTARY THERAPIES AND PLAYFUL ACTIVITIES

\section{ATENCIÓN DE ENFERMERÍA A LAS MADRES/CUIDADORAS DE NIÑOS Y ADOLESCENTES CON NECESIDADES ESPECIALES: TERAPIAS COMPLEMENTARIAS Y ACTIVIDADES LÚDICAS}

Vera Lucia Freitag ${ }^{1}$ Danieli Samara Federizzi ${ }^{2}$ Viviane Marten Milbrath ${ }^{3}$ Sidnei Petroni ${ }^{4}$ Manoella Souza da Silva ${ }^{5}$

Doi: $10.5902 / 2179769231142$

Claudia Helena Corazza Kuhn ${ }^{6}$

RESUMO: Objetivo: promover ações como atividades lúdicas e terapias complementares numa perspectiva de promoção à saúde no cuidado às mães/cuidadoras de crianças/adolescentes com necessidades especiais em saúde por meio de um projeto de extensão. Método: relato de experiência de um projeto extensionista desenvolvido em uma Associação de Pais e Amigos dos Excepcionais, com mães/cuidadoras de crianças/adolescentes com necessidades especiais. O método adotado foi o grupo operativo, por meio de atividades lúdicas e terapias complementares, totalizando 13 encontros. Resultados: vínculo, integração grupal, auto expressão verbal e não verbal, aumento da autoestima, autocuidado e valorização pessoal. Houve satisfação frente às atividades proporcionadas, observada pelos métodos de avaliação. Conclusões: o trabalho desenvolvido constitui-se como elo entre teoria e prática e contribui para a troca de saberes e experiências entre acadêmicos e profissionais da área da saúde, em especial, a enfermagem com a sociedade, construindo vínculos e favorecendo o cuidado.

\footnotetext{
${ }^{1}$ Enfermeira. Doutoranda em Enfermagem pelo Programa de Pós-Graduação em Enfermagem da Universidade Federal do Rio Grande do Sul (PPGEnf/UFRGS). Professora do Curso de Enfermagem da Universidade de Cruz Alta (UNICRUZ). Porto Alegre, Rio Grande do Sul (RS), Brasil. E-mail: verafreitag@ hotmail.com

${ }^{2}$ Enfermeira. Especialista em Enfermagem em Ginecologia e Obstetrícia. Missal, Paraná (PR), Brasil. E-mail: danieli.federizzi@hotmail.com

${ }^{3}$ Enfermeira. Doutora em Enfermagem pelo PPGEnf/UFRGS. Professora da Faculdade de Enfermagem (FEn) e do PPGEnf da Universidade Federal de Pelotas (UFPel). Pelotas, RS, Brasil. E-mail: vivianemarten@hotmail.com

${ }^{4}$ Biólogo. Doutor em Anatomia pela Universidade Estadual Paulista Júlio de Mesquita Filho (UNESP). Professor Adjunto II da Universidade Federal de Santa Maria (UFSM) - Campus Palmeira das Missões. Palmeira das Missões, RS, Brasil. E-mail: sidneipetroni@yahoo.com.br

${ }^{5}$ Enfermeira. Enfermeira Assistencial da Unidade de Cuidados Intermediários Neonatais do Hospital Santo Antônio de Blumenau, Santa Catarina (SC), Brasil. E-mail: manoellasouza@msn.com

${ }^{6}$ Psicóloga. Mestre em Psicologia Clínica pelo Programa de Pós-Graduação em Psicologia da Universidade do Vale do Rio dos Sinos (PPGPsico/UNISINOS). Palmeira das Missões, RS, Brasil. E-mail: corazza.claudia@gmail.com
} 


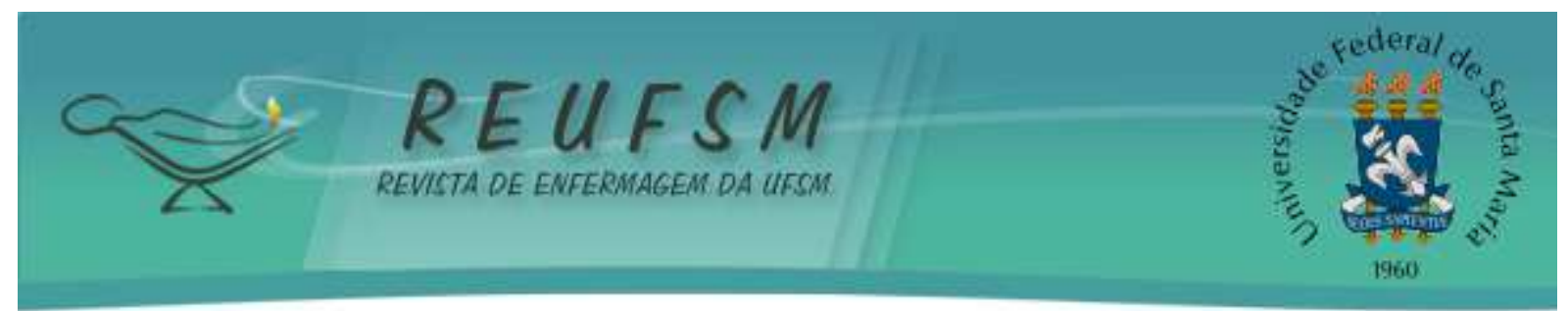

Descritores: Promoção da saúde; Educação em saúde; Cuidados de enfermagem; Terapias complementares; Cuidadores.

ABSTRACT: Aim: to promote actions such as recreational activities and complementary therapies in a health promotion perspective in the care to mothers/caregivers of children/adolescents with special health care needs by means of an extension project. Method: case studies of an extension project developed in an Association of Parents and Friends of the Mentally Ill, with mothers/caregivers of children/adolescents with special needs. The adopted method was the operating group, through recreative activities and complementary therapies, in a total of 13 meetings. Results: the bonding, group integration, verbal and non-verbal self expression, increased self-esteem, self-care and personal appreciation. There was satisfaction from the offered activities, observed by evaluation methods. Conclusions: work is a link between theory and practice and contributes to the exchange of knowledge and experience between academics and health professionals, in particular nursing with society, building bonds and favoring care.

Descriptors: Health Promotion; Health Education; Nursing Care; Complementary Therapies; Caregivers.

RESUMEN: Objetivo: promover acciones, como actividades recreativas y terapias complementarias, en una perspectiva de promoción de la salud, en el cuidado a las madres y cuidadores de niños y adolescentes con necesidades de atención especial de salud, por medio de un proyecto de extensión. Método: estudio de caso de un proyecto de extensión desarrollado en la Asociación de Padres y Amigos de Mentalmente Enfermos, con las madres y cuidadoras de niños y adolescentes con necesidades especiales. El método adoptado fue el grupo operativo, a través de actividades recreacionales y terapias complementarias, totalizando 13 encuentros. Resultados: conexión, integración grupal, expresión verbal y no verbal propia, mayor autoestima, autocuidado y apreciación personal. Hubo satisfacción delante de las actividades ofrecidas, observada por medio de métodos de valoración. Conclusiones: el trabajo desarrollado se constituí como enlace entre teoría y práctica y contribuye para el intercambio de conocimientos y experiencias entre académicos y los profesionales de la salud, en particular, la enfermería con la sociedad, construyendo vínculos y favoreciendo el cuidado.

Descriptores: Promoción de la Salud; Educación para la Salud; Atención de Enfermería; Terapias Complementarias; Cuidadores.

\section{INTRODUÇÃO}

O presente estudo aborda o tema decorrente de um projeto de mestrado sobre mães de crianças/adolescentes com paralisia cerebral em uma Associação de Pais e Amigos dos Excepcionais (APAE), intitulada: "Mãe de criança/adolescente com paralisia cerebral: compreensões sobre o cuidar de si como mulher". Os resultados da pesquisa indicam que as mães/cuidadoras carecem de autocuidado e convivem com sobrecargas diárias, que envolvem o cuidado da casa, dos outros filhos, e uma luta particular na busca de melhores condições de 


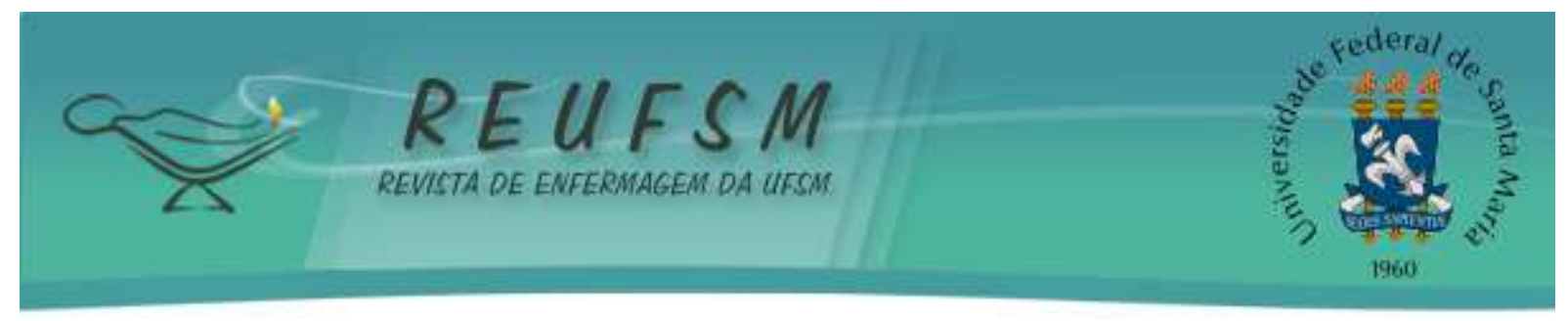

vida para o filho que vive esta situação, objetivando que este alcance o máximo de autonomia. Estas mães vivem para os filhos e pelos filhos, não encontrando tempo para cuidar de si. ${ }^{1}$

Diante disso, com o objetivo de fornecer retorno à instituição, local do desenvolvimento da pesquisa, estruturou-se um projeto extensionista que pudesse preencher parte da lacuna existente em relação ao cuidar de si destas mães/cuidadoras, e que fosse estendido a todas as mães que frequentam a APAE onde o projeto foi desenvolvido. $\mathrm{O}$ modelo de cuidado envolvendo grupos operativos pode oferecer subsídios para a prevenção, promoção, recuperação e reabilitação da saúde, propondo atividades que possam resgatar a autoestima das mães, diminuindo e/ou eliminando o estresse e a sobrecarga, produzindo a interação social.

Todavia, cabe destacar que o cuidado das mães às crianças/adolescentes com necessidades especiais é fundamental para o crescimento e desenvolvimento delas tendo como responsabilidade assumir os cuidados que os mesmos necessitam e estabelecer uma relação estreita de afeto para o seu crescimento saudável e bem estar. O cuidado demanda tempo e fidelidade a ele, especialmente, quando as crianças/adolescentes necessitam de cuidados especiais em saúde. Neste sentido, a mãe também precisa ser cuidada para cuidar do filho.

A enfermagem poderá cuidar dessas mães com ações que possam auxiliá-las a desenvolver suas potencialidades, facilitando o cuidar de si e do outro, visto que o cuidado compõe a linguagem da enfermagem e pode ser sugerido, recomendado, aconselhado. É uma ação independente da enfermagem que deve ser visualizada como um modo de ser, relacional, contextual que não pode ser prescrito, diferente de terapêuticas, técnicas, intervenções, procedimentos, pois não se prescreve um modo de ser, de cuidar, de comportar-se. Todavia, as ações desenvolvidas pelo cuidador podem ser expressas por meio de conhecimento, habilidades, criatividade, sensibilidade, pensamento crítico, julgamento e na capacidade de tomar decisões. O respeito, gentileza, compaixão, responsabilidade, disponibilidade, oferecimento de segurança, apoio, conforto, consideração e carinho fazem parte de comportamentos e atitudes da enfermagem. ${ }^{2}$

Neste sentido, dentre as ações, o enfermeiro poderá utilizar a promoção de saúde como ferramenta de cuidado, seguindo reorientação do Ministério da Saúde (MS). Tal ferramenta amplia o entendimento do usuário sobre seus problemas e, assim, favorece mudanças que podem possibilitar melhor qualidade de vida, colaborando na manutenção da saúde física e mental, do autocuidado, da autonomia e do empoderamento das pessoas. ${ }^{3-4}$ 


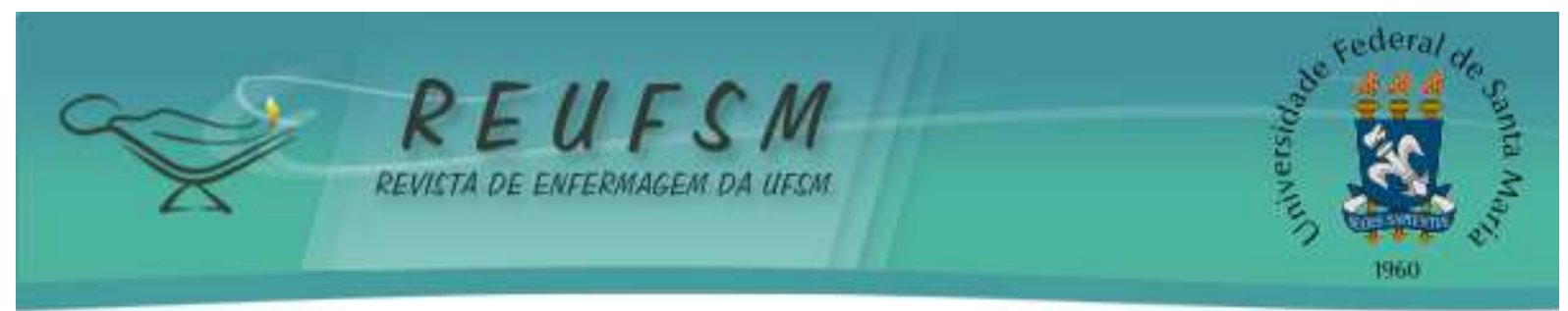

A convivência familiar, na qual há um membro com necessidades especiais em saúde, é afetada como um todo e pode comprometer as várias esferas psicológicas, emocionais, sociais e funcionais das unidades familiares. Por isso, vivem em uma condição complexa. Essa situação ocasiona estresse devido à cronicidade da deficiência, atribuindo diferentes desafios a cada etapa de vida do integrante da família que vivencia tal situação. ${ }^{5}$

Frente à grande demanda de cuidado dispensado à crianças/adolescentes com necessidades especiais, as mães/cuidadoras podem deixar de lado o ato de cuidar de si, ocorrendo desta forma, dificuldades frente à atenção contínua com sua saúde, o que pode gerar consequências desagradáveis, como o adoecimento e/ou a descoberta de doenças graves em estágio avançado. Para tanto, é necessário que estas dediquem parte do seu tempo para a realização de cuidados com sua mente e com seu corpo, adotando atitudes de promoção à sua saúde, qualidade de vida e bem estar e a prevenção de doenças, na medida em que também efetuem consultas e exames de rotina, rastreamento de agravos e estejam alertas a modificações notáveis do seu organismo, realizando, por exemplo, o autoexame das mamas.

Perante as fragilidades encontradas, há uma necessidade constante pela busca do cuidado de enfermagem, que se destaca como uma expressão da humanidade, essencial para o desenvolvimento e realização dos seres humanos. É o ato de cuidar que o profissional acrescentará em suas ações, sendo revestido de um conhecimento próprio, de sensibilidade, intuição, valores e princípios morais. Nesta premissa, cuidar constitui-se de uma atitude moral que deve ser exercida por todos os profissionais, envolve amor, solidariedade, preocupação primordial, consideração e conhecimento, corresponde ao ajudar incondicionalmente, oferecendo apoio, segurança, simpatia, compaixão e solidariedade. $^{6}$

A proposta de intervenção do grupo operativo integrado por mães/cuidadoras de crianças/adolescentes com necessidades especiais teve por objetivo promover ações como atividades lúdicas e terapias complementares numa perspectiva de promoção à saúde no cuidado a estas mães de crianças/adolescentes com necessidades especiais em saúde por meio de um projeto de extensão. 


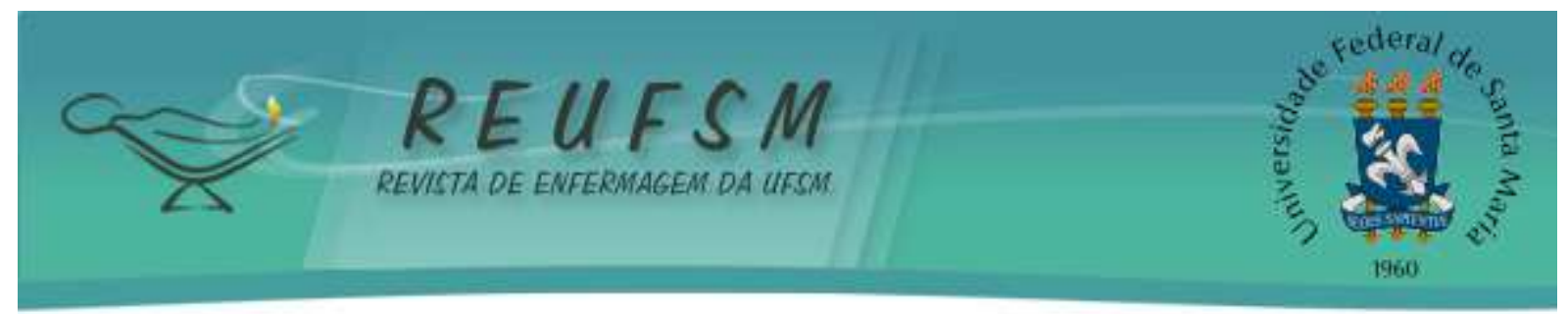

\section{MÉTODO}

Trata-se de um relato de experiência sobre o desenvolvimento de um projeto da Universidade Federal de Santa Maria (UFSM)/Campus Palmeira das Missões, registrado no Gabinete de Projetos sob o número 042352. Foi desenvolvido em uma APAE localizada em um município da Região Norte do estado do Rio Grande do Sul - Brasil, com as mães/cuidadoras de crianças/adolescentes com necessidades especiais em saúde, que frequentam esta instituição. $\mathrm{O}$ método adotado para as atividades extensionistas foi o grupo operativo, desenvolvido por meio de atividades lúdicas como: dinâmicas, gincana, música, dança, videoteca, desenho, pintura, filme, sessão de anedotas, colagens, dia de princesa e Práticas Integrativas e Complementares, como reiki e meditação.

O grupo extensionista foi composto por uma enfermeira professora do curso de enfermagem, uma doutoranda em enfermagem, um biólogo professor que ministra aulas para o curso de enfermagem e uma acadêmica de graduação em enfermagem, bolsista do projeto de extensão, a qual desenvolve os grupos operativos, com auxílio da equipe extensionista e a psicóloga da instituição.

As Práticas Integrativas e Complementares (PIC) são regulamentadas pela Política Nacional das Práticas Integrativas e Complementares (PNPIC), que reconhecem diversas práticas complementares de saúde desenvolvidas em inúmeros municípios e Estados. Estas práticas são caracterizadas pela abordagem integral no cuidado à saúde, buscando estimular mecanismos naturais de prevenção de agravos e recuperação da saúde. ${ }^{7}$

Atualmente há importantes avanços no campo das PIC no cenário nacional. O MS publicou a Portaria ${ }^{\circ}$ 849/2017 que inclui mais 14 PIC na PNPIC, a destacar: arteterapia, ayurveda, biodança, dança circular, meditação, musicoterapia, naturopatia, osteopatia, quiropraxia, reflexoterapia, reiki, shantala, terapia comunitária integrativa e yoga. ${ }^{8}$

O grupo operativo é entendido como o conjunto de pessoas ligadas entre si por constantes de tempo e espaço, articulada por sua mútua representação interna que se propõe de forma explícita ou implícita a uma tarefa, constituindo-se na sua finalidade. Cada participante é diferente e exercita sua fala, sua opinião, seu silêncio, defendendo seu ponto de vista. ${ }^{9}$

Inicialmente, a equipe extensionista participou de uma reunião desenvolvida pelos profissionais da instituição em questão, a fim de expor a proposta do trabalho, objetivos e atividades a serem desenvolvidas, justificando a importância de um olhar mais aguçado para estas 


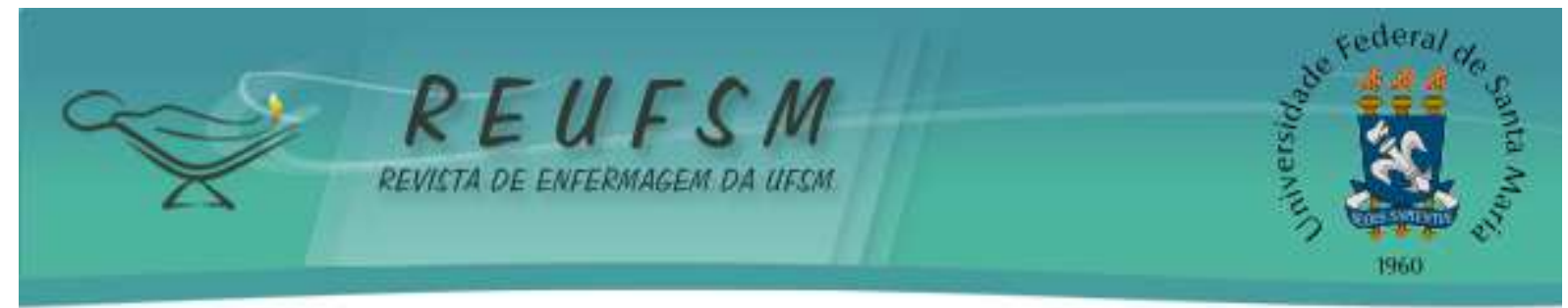

mães/cuidadoras. Posteriormente, foi elaborado em conjunto com a psicóloga da instituição, responsável pelo desenvolvimento das atividades em grupo, um cronograma com as atividades que seriam desenvolvidas, bem como as datas prováveis das ações extensionistas.

Tendo em vista a concretização dos objetivos, as atividades foram desenvolvidas com o grupo de mães na APAE, em sala reservada para recreação, com duração média de 90 minutos, estendendo-se, algumas vezes, de acordo com a necessidade e a disponibilidade das participantes. Ao final de cada encontro realizou-se uma avaliação oral livre dos trabalhos desenvolvidos, para aprimorar o grupo e proporcionar autonomia para as integrantes socializarem dúvidas e saberes, bem como propor atividades para os próximos encontros. No quarto e oitavo encontros, as participantes realizaram o preenchimento manual de uma ficha de avaliação das atividades desenvolvidas, que serviram de subsídios para o aperfeiçoamento dos próximos trabalhos sociais a serem desenvolvidos pelo grupo extensionista. Os encontros, num total de treze, aconteceram quinzenalmente, elaborados e coordenados pela equipe extensionista com a colaboração da psicóloga da APAE.

O quadro, a seguir, representa as atividades desenvolvidas com as mães/cuidadoras de crianças/adolescentes na Associação de Pais e Amigos dos Excepcionais.

Quadro I. Atividades desenvolvidas nos respectivos encontros.

\begin{tabular}{|c|l|}
\hline Ordem dos encontros & \multicolumn{1}{|c|}{ Atividade desenvolvida } \\
\hline $1^{\mathbf{o}}$ & Dinâmicas e desenho autoexpressivo \\
\hline $2^{\mathbf{o}}$ & Sessão de filme e pipoca \\
\hline $3^{\mathbf{o}}$ & Trabalhos artísticos \\
\hline $4^{\mathbf{o}}$ & Gincana \\
\hline $5^{\mathbf{o}}$ & Meditação e autoestima \\
\hline $6^{\mathbf{o}}$ & Terapia Complementar Reiki \\
\hline $7^{\mathbf{0}}$ & Artesanatos \\
\hline $8^{\mathbf{o}}$ & Atividade física e dança \\
\hline $9^{\mathbf{o}}$ & Outubro Rosa \\
\hline $10^{\mathbf{o}}$ & $\begin{array}{l}\text { Roda de conversa sobre o relacionamento entre as } \\
\text { mães/cuidadoras e crianças/adolescentes com necessidades } \\
\text { especiais sessão de }\end{array}$ \\
\hline $11^{\mathbf{o}}$ & $\begin{array}{l}\text { Dicas e curiosidades sobre saúde e beleza e sede } \\
\text { anedotas }\end{array}$ \\
\hline $12^{\mathbf{o}}$ & Dia de princesa \\
\hline $13^{\mathbf{o}}$ & Encerramento das atividades do grupo \\
\hline & \\
\hline
\end{tabular}




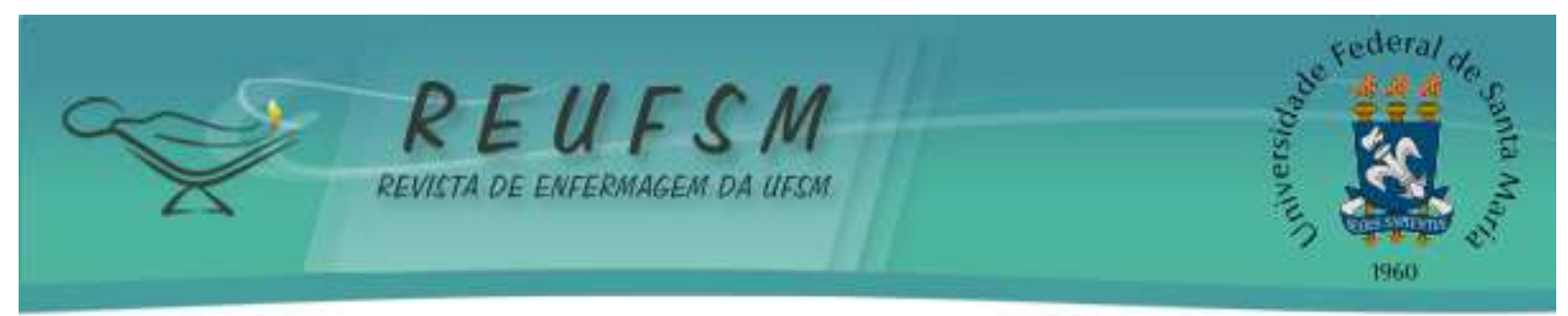

\section{RESULTADOS E DISCUSSÕES}

As ações extensionistas vieram ao encontro das expectativas da equipe de profissionais e do público alvo, visto a existência de fragilidades encontradas pela falta de atividades desenvolvidas na APAE que envolvessem diretamente estas cuidadoras, uma vez que a maioria direciona-se, exclusivamente, aos cuidados com a crianças/adolescentes com algum tipo de necessidade especial.

As práticas realizadas em cada encontro sustentaram-se no objetivo de integração grupal e valorização pessoal, a partir de dinâmicas interativas entre os participantes que favoreceram a auto expressão verbal e não verbal, o envolvimento e a empatia, assim como o reconhecimento dos próprios valores, na medida em que virtudes e valores foram contemplados de maneira divertida, fortalecendo a autoestima das participantes.

A atividade lúdica constitui-se como componente do processo de aprendizagem, e representa uma ferramenta de relevância por tornar o ato de aprender, belo, prazeroso e contribuir para o desenvolvimento do indivíduo como um todo. ${ }^{10}$ Este processo de aprendizagem beneficia o desenvolvimento da linguagem, do pensamento, da socialização, da iniciativa e da autoestima, transmitindo ao indivíduo capacidade para enfrentar desafios e participar na construção de um mundo melhor. O brincar e o jogar representam atos indispensáveis à saúde física, emocional e intelectual do ser humano, ${ }^{11}$ além de ser uma excelente maneira de descontração para as mães/cuidadoras de crianças/adolescentes com necessidades especiais em saúde.

A participação em atividades sociais em grupo pode causar um impacto positivo sobre a saúde mental das cuidadoras dessas crianças, como interrupção temporária da realidade, reduzindo os níveis de angústia, além de permitir um olhar para si, vivenciando um momento seu.

Na mesma perspectiva, um trabalho desenvolvido com grupos de gestantes, com o objetivo de conhecer as motivações das mães/cuidadoras e identificar a repercussão de sua participação em atividade de grupo operativo de gestantes destacou que o encontro se constituiu como um espaço de reflexão, de escuta, de diálogo, de troca de saberes e experiências, além de auxiliar na formação de laços de amizade entre as participantes e com a equipe multiprofissional. Conviver com pessoas diferentes de sua comunidade oportunizou a ampliação das relações interpessoais e a construção de novas redes sociais. Ademais, a 


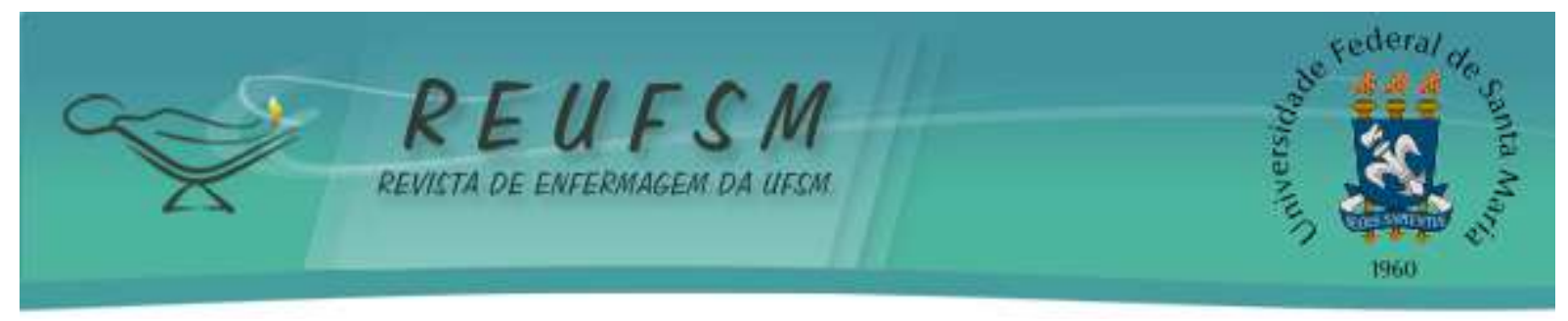

dialogicidade da prática educativa constituída durante os encontros viabilizada pela troca de informações entre as mães, favoreceu a humanização e a integralidade da atenção, dispositivos qualificadores do processo de promoção da saúde. ${ }^{12}$

Durante o desenvolvimento do projeto foram proporcionadas atividades envolvendo música e dança, a partir do desenvolvimento de uma gincana com o grupo, a fim de proporcionar momentos de descontração e alegria. A expressão corporal por meio de sons e ritmos traz consigo um processo de evolução e integração social. A dança em ambiente livre, realizada no oitavo encontro contou com a participação especial de uma professora de dança convidada para desenvolver momentos lúdicos com as mães/cuidadoras, compreendendo atividades de alongamento e respiração, passos simples de dança de forma individual e coletiva, utilizando diversos estilos musicais, e também brincadeiras com música e dança.

O momento lúdico promovido pela música é um recurso importante que promove o autocuidado ao proporcionar relaxamento, bem-estar e prazer de estar consigo mesmo e com o outro. A busca do prazer e a preocupação com a qualidade de vida são valorizadas à medida que favorecem o desejo do outro, ampliando a visão do que se considera um sistema de cuidado. A música pode atuar na redução dos níveis de ansiedade, dor e relaxamento, atenuando o estresse e melhorando o sono, além de contribuir para a comunicação e expressão, além de o simples ato de ouvir, harmonizar corpo e mente. ${ }^{13}$

A mudança de paradigma na enfermagem em busca de novas maneiras de cuidar do ser humano, quando pautadas na ética, gera mudanças na visão não somente do outro, mas de si mesma. Dentre estas mudanças, a utilização da música configura-se como uma aliada na assistência de Enfermagem. Na história da Enfermagem, em 1859, a música começou a ser utilizada com a finalidade terapêutica por Florence Nightingalee mencionava que a utilização da música era um cuidado à saúde. Em hospitais, a pioneira foi a enfermeira e musicista Isa MaudIlsen, que criou a Associação Nacionalde Música nos Hospitais, ensinou musicoterapiana Universidade de Columbia e HarryetAyer Seymour, depois de observar soldados feridos das I e II Guerras Mundiais, dedicou-se à terapêutica musical por meio de método próprio. Preocupada com o tema, abriu uma escola para formação de musicistas para tocar à beira do leito de pessoas hospitalizadas e fez vários concertos para milhares de doentes nos Estados Unidos, por acreditar que auxiliaria na recuperação das pessoas e instigar o movimento, a dança. ${ }^{14}$ 


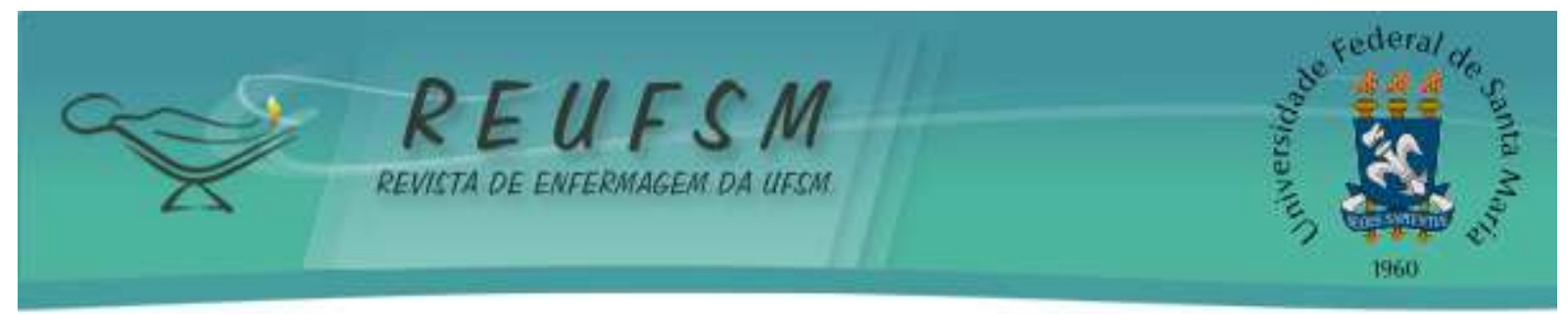

A dança é entendida como uma manifestação histórica, social e cultural, portanto, caracteriza-se como um fenômeno de linguagem corporal artística. Sob essa ótica, caracterizase por uma atividade corporal alegre, favorecendo sensações de bem-estar e elevando a autoestima e a motivação de quem a pratica. Além disso, a dança, enquanto atividade física, traz diversos benefícios para a saúde, pois além do bem-estar psíquico e emocional que ela carrega, auxilia, ainda, na melhoria da elasticidade muscular e das articulações, diminui o risco do surgimento de doenças cardiovasculares, e, também, dos problemas locomotores e do sedentarismo. ${ }^{15} \mathrm{O}$ dia a dia destas mães configura-se pelo cuidado ao filho, além das dificuldades relacionadas ao convívio social e sobrecarga emocional. A sobrecarga física é fator que interfere na qualidade de vida, as dores, em especial as lombares, são frequentes devido aos esforços físicos dispensados no cuidado, visto que muitas crianças/adolescentes não tem atividade locomotora. ${ }^{1,16}$

Dessa maneira, pode-se perceber que a dança, como atividade física, melhora a saúde e a qualidade de vida de quem a pratica por meio dos movimentos corporais. Assim, o número de pessoas interessadas em praticar essa atividade vem crescendo significativamente, pelo fato de a atividade proporcionar alegria e diversão aos praticantes, sendo esta uma fonte de bem-estar, melhora do desempenho físico e integração social, podendo ser ponderada como uma terapia motivacional pelo prazer que propicia aos indivíduos. ${ }^{17}$

Junto ao grupo operativo, também foram elaborados trabalhos artísticos, a partir de oficinas com atividades de desenho, colagem e elaboração de cartão, pintura em pano de prato e decoração de objetos em que as mães/cuidadoras puderam participar conforme sua preferência pessoal. Este momento recreativo proporcionou entrosamento entre as participantes, bem como a ampliação da criatividade e do empenho, acompanhado de alegria, diversão e arte. No encontro dedicado à atividade de artesanato, muito solicitado pelas participantes, trabalhou-se com a decoração de recipientes de vidro, utilizando-se tinta, tecido e fita, e a confecção de porta objetos, elaborados com garrafa pet e decorados com Etil Vinil Acetato (EVA), fitas e figuras.

Nesses momentos de expressão da arte, a experiência proporciona a comunicação por meio da auto expressão, seja ela verbal ou não verbal; seja objetiva ou subjetiva, permitindo pensar a oficina como espaço relacional do qual o indivíduo é integrante, aderindo aos direitos e deveres que tornam sua participação efetiva, permitindo a construção de relações 


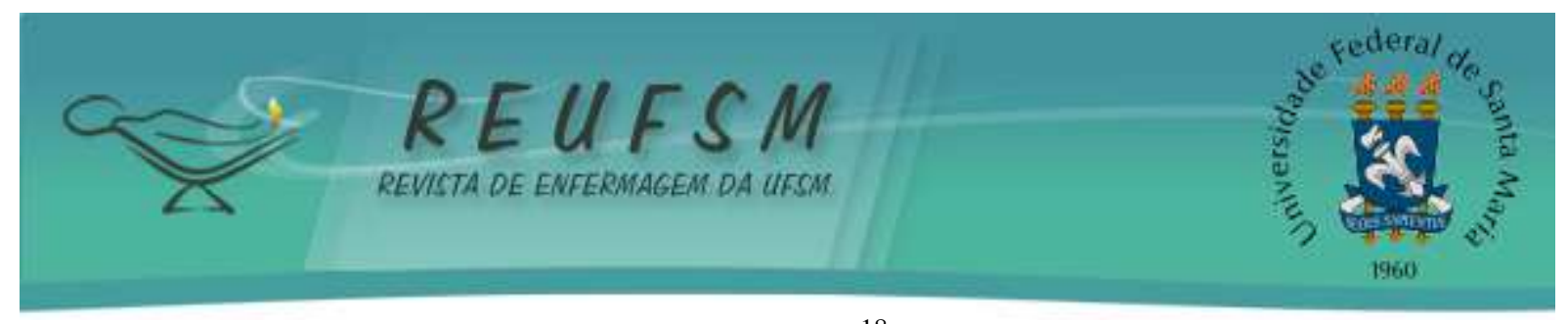

interpessoais saudáveis por meio das interações. ${ }^{18}$ Assim, entende-se que seja importante desenvolver estas atividades lúdicas no processo de cuidar da enfermagem, pois elas fazem parte da vida humana e possuem um importante papel na etiologia humana.

Dessa forma, a promoção da saúde configurada pela demanda da população, possibilita à enfermagem uma nova maneira de pensar, conceber e sistematizar a assistência em saúde, compreendendo que o cuidado não é prescritivo, vem de uma demanda do ser cuidado, baseado na sua multidimensionalidade, levando em conta sua cultura, sua maneira de pensar, viver e ser no mundo, proporcionando seu desvelar.

Os diversos encontros foram organizados no sentido de possibilitar a auto-expressão, de modo geral com as atividades divertidas, a exemplo das sessões de piadas, anedotas e a sessão filme e pipoca com a passagem do filme "Sim Senhor", uma comédia de Jim Carrey, que instigou uma discussão sobre as lições de vida apreendidas e expressão de sorrisos.

Com relação às atividades alusivas ao Outubro Rosa, foram desenvolvidas dinâmicas coletivas, tendo por objetivo a expressão de afeto, o despertar de valores e a autoestima, seguidas de uma apresentação em Power point, sobre o tema: Outubro rosa, mulher consciente na luta contra o câncer de mama, em que foram abordados aspectos relacionados à origem da campanha e ao câncer de mama: epidemiologia e fisiologia, fatores predisponentes, sinais e sintomas, prevenção, detecção precoce, autoexame, mamografia, ecografia e biópsia. O tema foi discutido de forma dinâmica, utilizando o método roda de conversa e proporcionando a interação das participantes a partir de dúvidas, contribuições e depoimentos. Em seguida, o grande grupo foi convidado a dispor-se diante do espelho para realizar a simulação do autoexame de mama, guiadas pela coordenadora do encontro, e, na sequência, um vídeo sobre o tema discutido para complementar e ilustrar o assunto. O encontro foi finalizado com duas dinâmicas, um jogo de perguntas e respostas sobre o tema contemplado e uma outra abordando a autoestima.

Utilizou-se oportunamente o movimento Outubro Rosa como momento para instigar as participantes do projeto extensionista no controle do câncer de mama, visto ser uma doença decorrente da multiplicação de células anormais do tecido mamário, com cerca de $25 \%$ de casos novos anuais, e, aproximadamente, $28 \%$ dos casos de câncer em mulheres, e para o ano de 2016 terem sido estimados, aproximadamente, 58 mil novos casos da doença. ${ }^{19}$

Considerando a importância da detecção precoce do câncer de mama para a redução 


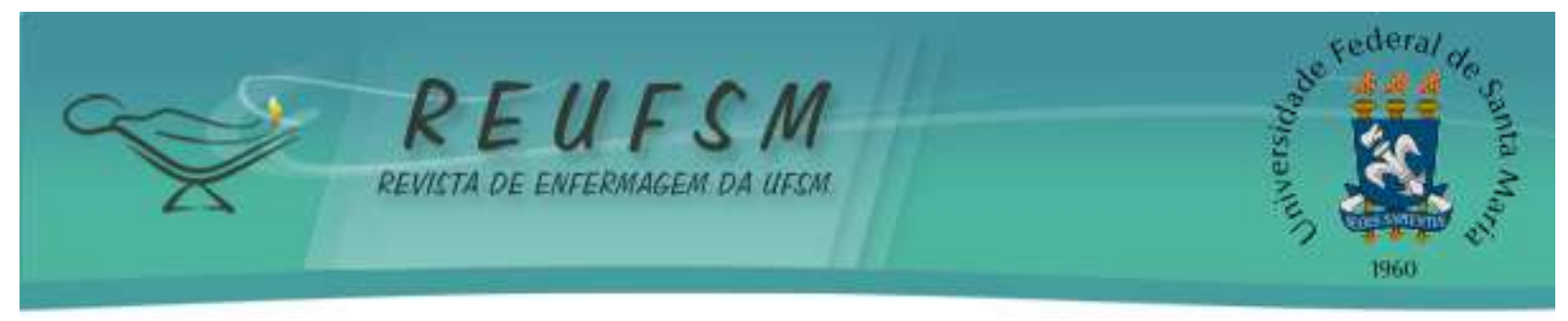

das taxas de mortalidade, a julgar pela alta incidência da doença em mulheres em idade fértil, o encontro que abordou essa temática buscou conscientizar as participantes sobre a importância de conhecer o próprio corpo, atentando para sinais importantes mas, principalmente, para esclarecer dúvidas sobre a doença e, ainda, sobre sua detecção precoce, com o intuito de facilitar a adesão aos exames preventivos tendo em vista a importância destes para a garantia da qualidade de vida e de saúde das mulheres.

Tais atividades desenvolvidas pela enfermagem estão de acordo com a Política Nacional de Promoção de Saúde, pois esta expõe que a promoção da saúde é uma estratégia de desenvolvimento de ações que conferem visibilidade aos fatores que colocam a saúde populacional em risco, levando em conta aspectos territoriais e culturais, visando à criação de mecanismos que reduzam as situações de vulnerabilidade e aumentando a eficiência e a efetividade das políticas públicas existentes. ${ }^{20}$

Na sequência do desenvolvimento dos encontros, vídeos ilustrativos de "como ter a mente equilibrada por meio de sete afirmativas" e "o que a mente humana é capaz de fazer", foram exibidos, proporcionando reflexões e troca de opiniões, em um encontro motivacional. Estabeleceu-se uma roda de conversa com as mães/cuidadoras, relacionada à díade mães/cuidadoras e crianças/adolescentes com necessidades especiais, gerando reflexões diversas sobre as facilidades, dificuldades, dúvidas e experiências desta relação, por meio de uma abordagem criativa e de incentivo ao bom relacionamento. Buscou-se conhecer melhor a história dessas mulheres e o relacionamento com seus filhos ou familiares; em seguida, as mães/cuidadoras confeccionaram cartões para as crianças/adolescentes expressando seus sentimentos em relação a eles. Este encontro proporcionou a auto expressão das mulheres, diante do compartilhamento de suas vivencias, obstáculos, preocupações e alegrias com o grupo. Ao expor suas dúvidas e compartilhar suas experiências, elas se sentiram acolhidas ao compartilhar as adversidades encontradas no dia a dia.

Assim, observou-se que o enfermeiro necessita desempenhar um importante papel frente às ações direcionadas ao cuidado da família, em especial à mãe. As atividades que estimulam a auto expressão, favorecem a manifestação da subjetividade ${ }^{21}$ e assim, oportunizam a compreensão da vida destas mães/cuidadoras, auxiliando-as no cuidar de si por meio das reflexões. 


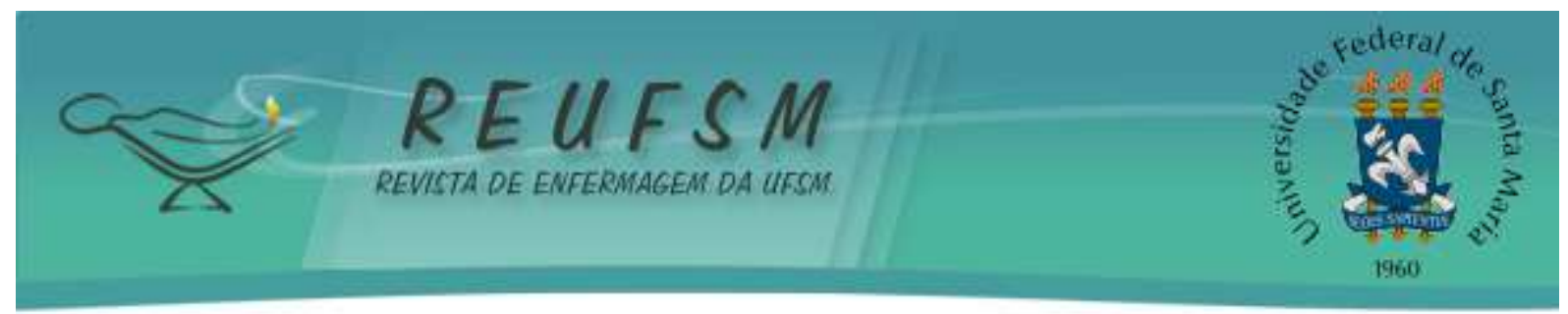

Nesta perspectiva, o encontro concretizou-se um momento de reflexão e discussão acerca dos medos, desafios e dificuldades frente a situações, bem como as expectativas para o novo ano que se aproximava. Além do momento de entrosamento do grupo, proporcionou-se um momento de compartilhar experiências, vivências, medos, dificuldades, expectativas, objetivos e metas. Neste encontro optou-se, também, por compartilhar dicas e curiosidades sobre saúde, beleza e bem-estar, a partir de roda de conversa, troca de experiência e dinâmicas interativas.

O dia de princesa foi programado com uma empresa de salão de beleza que, gentilmente, esteve na APAE ofertando serviços de corte e penteado de cabelo, manicure e maquiagem. $\mathrm{O}$ objetivo deste encontro foi proporcionar às participantes uma tarde de beleza e cuidado com seu próprio corpo, promovendo o aumento da autoestima e a atenção consigo, permitindo-se um momento próprio de bem estar e relaxamento, percebendo-se como mulher que também necessita e merece cuidados.

Tais atividades grupais configuram-se como novos modelos de promover saúde e produzir conhecimento científico. Na visão de alguns autores ${ }^{22}$, a enfermagem em diversos temas em saúde, ultrapassa os limites institucionalizados com atividades que vão ao encontro de políticas e modelos de atenção à saúde, com uma nova abordagem acerca do conceito saúde, de enfermagem, de cuidado de enfermagem, de viver saudável, de comunidade vulnerável, de empreendedorismo social em enfermagem. Este pensamento complexo, somente pode ser compreendido a partir de um saber que os integra, articula e complementa, buscando perceber e promover a interatividade e a complementaridade de fenômenos que fazem parte de uma unidade.

Relacionados aos momentos de abordagem às PIC proporcionaram-se técnicas de reiki e meditação em encontros distintos. As atividades de meditação foram praticadas em uma sala preparada com tatames, a fim de que as participantes pudessem acomodar-se da melhor maneira, iniciando por atividades preparatórias de alongamento e respiração e, de imediato, o exercício de meditação durante a leitura de um texto reflexivo, acompanhado de um fundo musical específico para a prática e a finalização da atividade com uma mensagem de autoestima e um vídeo motivacional.

A meditação pode ser compreendida por um estado de pura concentração, em que a mente flui livre e naturalmente em direção à consciência cósmica. É um esforço para controlar, desenvolver e expandir a mente, a fim de realizar a verdadeira natureza do ser e 


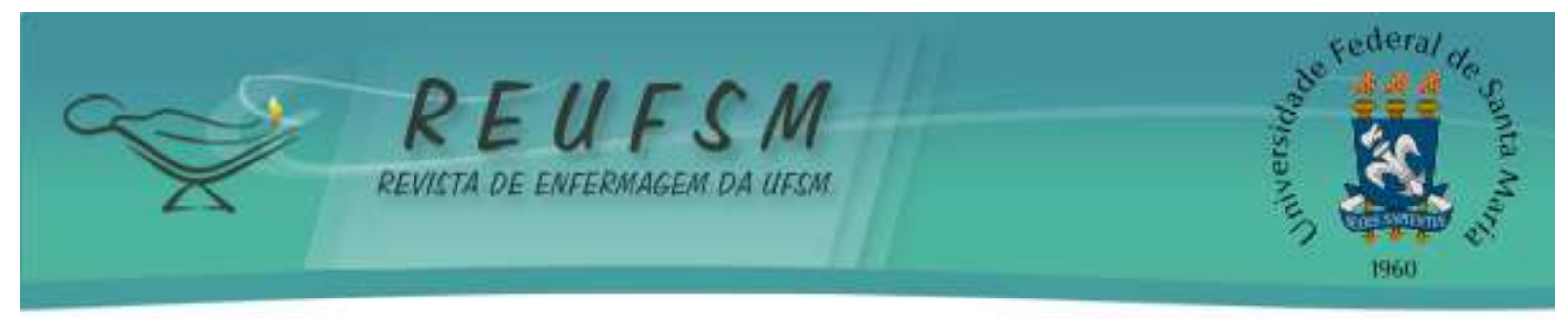

desenvolver todo o nosso potencial em todos os níveis da existência: físico, mental e espiritual. Afeta diretamente o corpo ao estabelecer alterações fisiológicas e, indiretamente, ao criar uma sensação de equilíbrio interior. A prática vem sendo evidenciada como uma excelente ferramenta para o relaxamento do indivíduo, proporcionando alterações fisiológicas que podem diminuir sintomas provenientes do estresse, da fadiga, da ansiedade, da hipertensão, das doenças cardíacas, da depressão, do pânico, entre tantas outras. ${ }^{23}$

Esta atividade permitiu aos participantes construírem painéis utilizando materiais de pintura, desenho e recorte de imagens, e após, uma apresentação individual dos painéis expressando seu significado. Nesse encontro, o relaxamento e a reflexão foram pontos fundamentais obtidos com as atividades, os sorrisos e o entrosamento entre as participantes durante a confecção dos painéis, a alegria durante sua exposição e a contribuição com falas durante as discussões reflexivas foram de grande crescimento individual e coletivo.

A melhora da qualidade de vida de uma população faz parte do cuidado de enfermagem, e este assume dimensões ampliadas nos diferentes cenários e áreas de atuação profissional, configurando-se como novas maneiras de intervir no processo saúdedoença, envolvendo modos de ser, produzir e recriar a vida em sua singularidade e multidimensionalidade. Estes encontros permitem a dialogicidade do grupo, a interatividade, potencializando o viver saudável pelo desenvolvimento de práticas e ações empreendedoras. Tais atividades podem efetivamente contribuir para um novo pensar e agir na saúde e cuidado de enfermagem. ${ }^{22}$

No encontro preparado para a aplicação do reiki, foram abordados aspectos sobre sua história, significado, aplicabilidade, benefícios, curiosidades, além de sanar as dúvidas das participantes. As sessões foram realizadas individualmente em uma sala preparada com tatames e música relaxante. Salienta-se que as sessões desta terapia foram aplicadas pela coordenadora das atividades que possui curso reiki nível 1. As demais mães/cuidadoras que aguardavam pela sessão, permaneciam na sala inicial na presença da psicóloga da APAE e tendo à disposição materiais sobre a terapia reiki (livros e apostilas).

O reiki constitui uma prática complementar caracterizada pela imposição das mãos do doador em forma de concha direcionando a energia de cura para o corpo do receptor, sendo que esta posição das mãos corresponde ao sistema de glândulas endócrinas do corpo e aos 


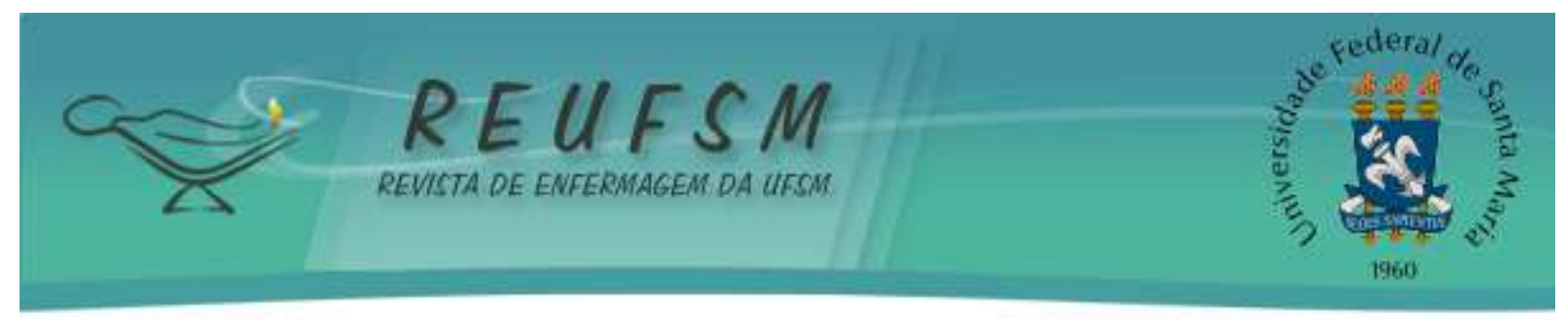

sete chakras principais, ou centros de energia, com o objetivo de equilibrar as dimensões física, mental e espiritual do ser humano. ${ }^{24}$

Em estudo realizado com aplicação de reiki em pessoas idosas com dor crônica, os resultados apontaram a ativação da energia, o alívio das dores e a promoção de relaxamento corporal, diminuindo a ansiedade. ${ }^{25}$ Neste sentido, tais experiências com PICs foram positivas para a equipe extensionista, pois propiciaram uma reflexão sobre o cuidar do enfermeiro, o qual vai além do biológico, havendo necessidade de buscar novas ferramentas de cuidado que possam promover saúde e auxiliar na melhora da qualidade de vida.

As diversas atividades desenvolvidas no grupo operativo foram de relevância pessoal e social, geradoras de resultados positivos e do estabelecimento de laços de amizade entre a extensionista e a equipe de saúde, com as participantes do grupo e entre as próprias participantes. A escolha das atividades e ações desenvolvidas em cada encontro proporcionou crescimento profissional e acadêmico relacionado ao conhecimento de enfermagem, trazendo ganhos positivos para a equipe extensionista.

Destarte, pode-se considerar que o desenvolvimento destas ações correspondeu às necessidades e desejos do público alvo, trabalhando todos os aspectos do ser de forma holística e humanizada, contribuindo de forma significativa e positiva para o aumento da autoestima das mães/cuidadoras e proporcionando momentos únicos e de cuidado consigo mesma. Estas atividades tiveram importância contributiva, visto a incerteza de projetos extensionistas relacionados com a temática abordada e público alvo correspondido, em que foi possível promover um elo entre comunidade e universidade, troca de conhecimentos e experiências, vivências únicas e proporcionar resultados positivos e benéficos para a qualidade de vida.

\section{CONCLUSÕES}

O objetivo do projeto de promover saúde por meio de grupos operativos às mães/cuidadoras participantes demonstrou a satisfação e a importância do grupo operativo para seu bem estar e autoestima, pois as atividades desenvolvidas proporcionavam momentos de relaxamento, diversão, descontração e ânimo para realizar suas atividades diárias, além disso, expressaram seu interesse em continuar frequentando o grupo. Relataram, ainda, a insatisfação por não poder participar de todos os encontros, devido a 


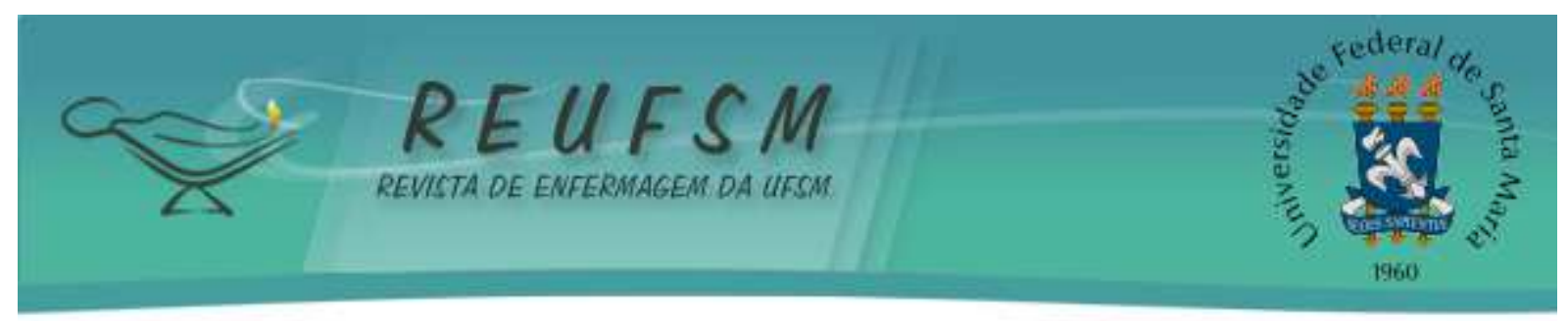

compromissos ou dificuldades de locomoção. Referente à avaliação por nota, as participantes ponderaram os encontros com notas expressivas, como 100 e 1000, evidenciando sua satisfação frente às atividades.

Assim, promover saúde por meio do cuidado de enfermagem a grupos operativos pelo projeto extensionista com diversas atividades lúdicas e interativas, práticas integrativas, influenciaram nas percepções positivas e modificações comportamentais das mães/cuidadoras de crianças/adolescentes com necessidades especiais visto que as mesmas, ao assumirem a vivência e responsabilidade pelo cuidado do filho, necessitam de momentos próprios de acompanhamento e incentivo como a participação em grupos de apoio e de educação em saúde, bem como a necessidade de fomentar uma rede de suporte social.

Os profissionais de enfermagem por meio do cuidado, podem contribuir com seus saberes e práticas para orientar as mães/cuidadoras de crianças/adolescentes com necessidades especiais a refletir sobre a necessidade de ter o "seu momento", ou seja, refletir acerca do seu contexto, sua história de vida e cuidados próprios que a ajudem no enfrentamento das adversidades cotidianas.

A partir das atividades grupais e do envolvimento com outras mães/cuidadoras ouvem e são ouvidas por pessoas que compartilham das mesmas situações, permitindo troca de experiências entre elas. Assim, projetos como este envolvendo grupos e atividades lúdicas propiciam vínculos entre os profissionais e extensionistas, entre as mães e extensionistas e também entre elas, contribuindo para o estreitamento de vínculos entre todos os envolvidos nesse processo do cuidado.

O trabalho extensionista constitui-se como um elo entre teoria e prática e contribui para a troca de saberes e experiências entre acadêmicos e profissionais da área da saúde com a sociedade, construindo vínculos e novas formas de agir em grupo em prol de resultados que vão ao encontro dos objetivos da população, levando vida, saúde e esperança àqueles que, muitas vezes, precisam apenas de um sorriso, de atenção e reconhecimento. Este elo favorece crescimento profissional e acadêmico, por promover saúde com ações de cuidado que estão além do modelo prescritivo, instigando a reflexão sobre a prática profissional, bem como o cuidar de si das mães/cuidadoras.

Entretanto, o relato apresentado apresentou algumas limitações como o número de acadêmicos disponíveis e com interesse em participar das ações, e pelo fato de a equipe 


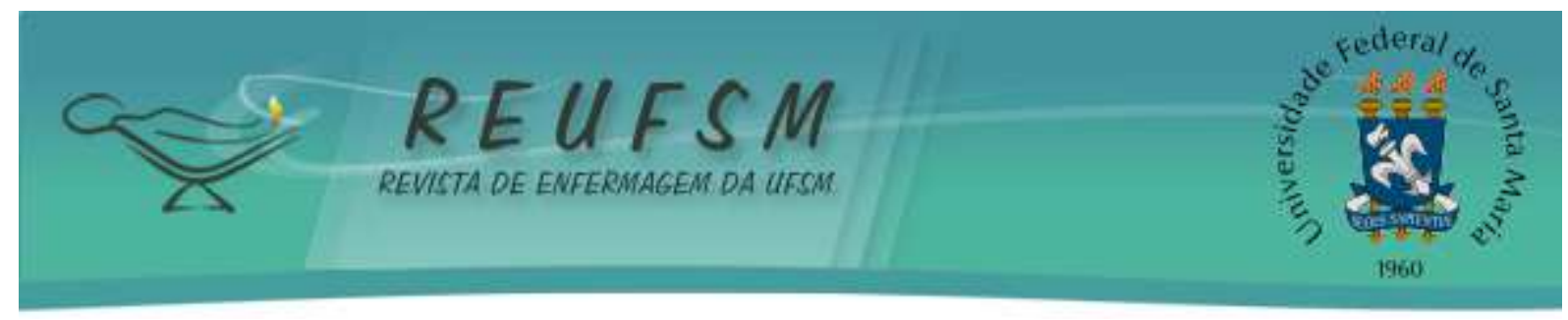

multiprofissional da APAE não contar com enfermeiro, o qual poderia desenvolver estratégias de cuidado, não somente às mães, mas à criança e sua família.

\section{REFERÊNCIAS}

1. Freitag VL, Milbrath VM, Motta MGC. Madre-cuidadora de niño/adolescente con parálisis cerebral: el cuidado de sí misma. Enfermería Glob [Internet]. 2018 abr [acesso em 2018 abr 24]; 17(2):325-36. Disponível em: http://revistas.um.es/eglobal/article/view/265821/226361.

2. Waldow VR. Enfermagem: a prática do cuidado sob o ponto de vista filosófico. Investigación en Enfermería: Imagen y Desarrollo [Internet]. 2015 [acesso em 2018 jun 25]; 17(1):13-25. Disponível em: http://www.redalyc.org/pdf/1452/145233516002.pdf.

3. Brasil. Ministério da Saúde. Secretaria de Atenção à Saúde. Departamento de Ações Programáticas Estratégicas. Política Nacional de Atenção à Saúde da Mulher : princípios e diretrizes [Internet]. Ministério da Saúde: Brasília (DF);2004 [acesso em 2018 jun 26]. Disponível em: http://bvsms.saude.gov.br/bvs/publicacoes/politica_nac_atencao_mulher.pdf.

4. Nogueira ALG, Munari DB, Fortuna CM, Santos LF. Pistas para potencializar grupos na Atenção Primária à Saúde. Rev Bras Enferm [Internet]. 2016 [acesso em 2018 jun 26];69(5): 964-71. Disponível em: http://www.scielo.br/pdf/reben/v69n5/0034-7167-reben-69-050964.pdf.

5. Santos MA, Pereira-Martins MLPL. Estratégias de enfrentamento adotadas por pais de crianças com deficiência intelectual. Ciênc Saude Colet [Internet]. 2016 [acesso em 2018 abr 24];21(10):3233-44. Disponível em: http://www.scielo.br/pdf/csc/v21n10/1413-8123-csc-2110-3233.pdf.

\section{Roselló FT. Antropologia do cuidar. Petrópolis (RJ): Vozes; 2009.}

7. Brasil. Ministério da Saúde. Portaria n. 971, de 03 de maio de 2006. Aprova a Política Nacional de Práticas Integrativas e Complementares (PNPIC) no Sistema Único de Saúde. [Internet]. Ministério da Saúde: Brasília (DF); 2006 [acesso em 2017 set 20]. Disponível em: http://bvsms.saude.gov.br/bvs/publicacoes/pnpic.pdf.

8. Brasil. Ministério da saúde. Portal da saúde. Portaria amplia oferta de PICS [Internet]. 2017 jan 13 [acesso em 2017 set 19]. Disponível em: http://dab.saude.gov.br/portaldab/noticias.php?conteudo=_\&cod=2297.

9. Pichon-Reviére E. O processo grupal. 7ª ed. São Paulo: Martins Fontes; 2009.

10. Silva TMD, Vargas, PL. O lúdico e a aprendizagem da pessoa com deficiência visual. Rev Pós-graduação: Desafios Contemporâneos [Internet]. 2014 [acesso em 2018 abr 24];1(1):13043. Disponível em: http://ojs.cesuca.edu.br/index.php/revposgraduacao/article/view/620.

11. Oliveira JC, Costa SD, Rocha SMB. Educação nutricional com atividade lúdica para escolares da rede municipal de ensino de Curitiba. Cad Esc Saúde [Internet]. 2017 [acesso em 2018 abr 24];2(6):100-16. Disponível em: http://portaldeperiodicos.unibrasil.com.br/index.php/cadernossaude/article/view/2333/1905. 


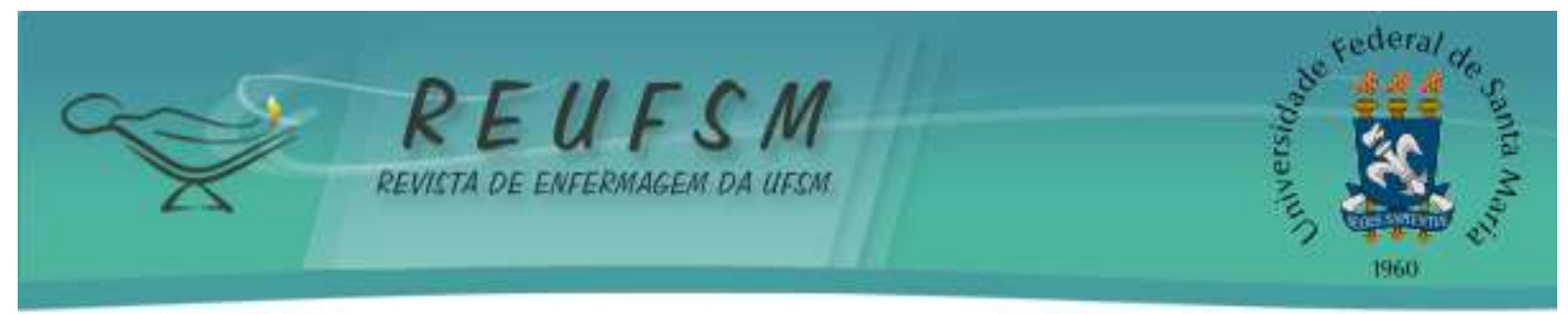

12. Maron LC, Cabral FB, Van der Sand ICP, Hildebrandt LM. Motivos e repercussões da participação de gestantes em grupo operativo no pré-natal. Rev Enferm UFSM [Internet]. 2015 [acesso em 2018 jun 26];4(3):519-28. Disponível em: https://periodicos.ufsm.br/reufsm/article/view/10827/pdf.

13. Zanettini A, Souza JB, Franceschi VE, Finger D, Gomes A, Santos MS. Quem canta seus males espanta: um relato de experiência sobre o uso da música como ferramenta de atuação na promoção da saúde da criança. REME Rev Min Enferm [Internet]. 2015 [acesso em 2018 abr 24];19(4):1060-4. Disponível em: www.reme.org.br/exportar-pdf/1058/v19n4a19.pdf.

14. Ribas JC. Música e Medicina. São Paulo: Edigraf; 1957.

15. Muglia-Rodrigues B, Correia WR. Produção acadêmica sobre dança nos periódicos nacionais de Educação Física. Rev Bras Educ Fís Esp [Internet]. 2013 [acesso em 2018 abr 24];27(1):91-9. Disponível em: https://www.revistas.usp.br/rbefe/article/view/53222/57280.

16. Almeida MS, Conceição TMA. Prevalência de sintomas álgicos, sobrecarga e qualidade de vida de cuidadores de crianças com paralisia cerebral. Rev Pesqui Fisioter [Internet]. 2013 jul [acesso em 2018 jun 26];3(1):36-49. Disponível em: https://www5.bahiana.edu.br/index.php/fisioterapia/article/view/143/179.

17. Marbá RF, Silva GS, Guimarães TB. Dança na promoção da saúde e melhoria da qualidade de vida. Rev Cient ITPAC [Internet]. 2016 [acesso em 2018 abr 24];9(1):1-9. Disponível em: https://assets.itpac.br/arquivos/Revista/77/Artigo_3.pdf.

18. Farias ID, Thofehrn MB, Kantorski LP. The therapeutic workshop as relational space in psychosocial care. Rev Urug Enferm [Internet]. 2016 out [acesso em 2018 abr 24];11(2). Disponível em: http://rue.fenf.edu.uy/index.php/rue/article/view/194/189.

19. Instituto Nacional do Câncer (INCA). Tipos de câncer: mama [Internet]. 2017 [acesso em 2017 nov 14]. Disponível em: http://www2.inca.gov.br/wps/wcm/connect/tiposdecancer/site/home/mama/cancer_mama.

20. Brasil. Ministério da Saúde. Secretaria de Vigilância em Saúde. Secretaria de Atenção à Saúde. Política Nacional de Promoção da Saúde [Internet]. 3a ed. Brasília: Ministério da Saúde; 2010 [acesso em 2017 nov 14]. Disponível em: http://bvsms.saude.gov.br/bvs/publicacoes/politica_nacional_promocao_saude_3ed.pdf.

21. Franzoi MAH, Santos JLGD, Backes VMS, Ramos FRS. Musical intervention as a nursing care strategy for children with autism spectrum disorder at a psychosocial care center. Texto \& Contexto Enferm [Internet]. 2016 [acesso em 2018 jun 25];25(1):e1020015. Disponível em: http://www.scielo.br/pdf/tce/v25n1/en_0104-0707-tce-25-01-1020015.pdf.

22. Backes DS, Zamberlan C, Colomé J, Souza MT, Marchiori MT, Erdmann AL, et al. Interatividade sistêmica entre os conceitos interdependentes de cuidado de enfermagem. Aquichan [Internet]. 2016 [acesso em 2018 jun 27];16(1):24-31. Disponível em: http://www.scielo.org.co/pdf/aqui/v16n1/v16n1a04.pdf.

23. Williams M, Penman D. Atenção plena - mindfulness. $1^{a}$ ed. Rio de Janeiro: Sextante; 2015. 208 p.

24. Honervogt T. Reiki cura e harmonia através das mãos. 14a ed. São Paulo: Pensamento; 2015. 144 p. 


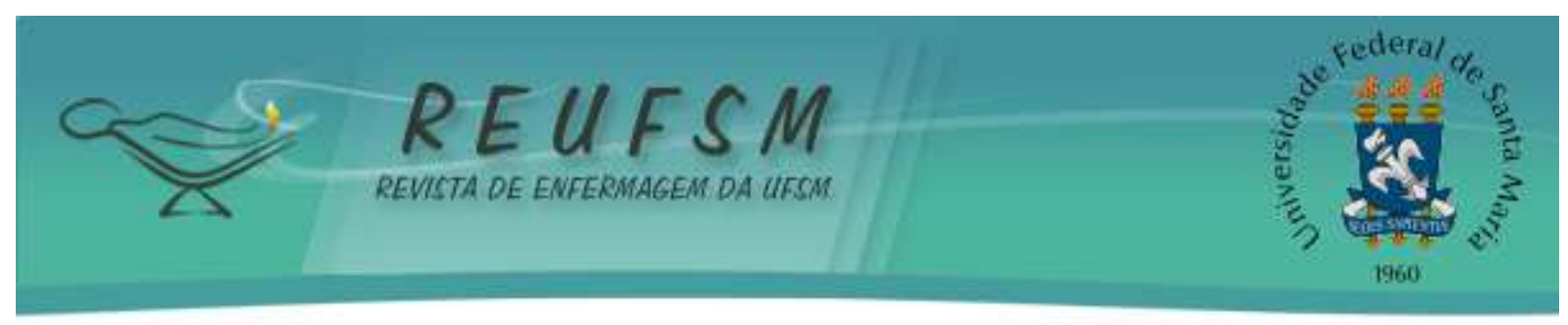

25. Freitag VL, Dalmolin IS, Badke MR, Andrade A. Benefícios do Reiki em população idosa com dor crônica. Texto \& Contexto Enferm [Internet]. 2014 out-dez [acesso em 2018 jun 27];23(4):1032-40. Disponível em: http://www.scielo.br/pdf/tce/v23n4/pt_0104-0707-tce-2304-01032.pdf.

Data de submissão: 10/02/2018

Data de aceite: $17 / 10 / 2018$

Autor correspondente: Vera Lucia Freitag

E-mail: verafreitag@ hotmail.com

Endereço: Rua São Manoel, no 963 - Bairro Rio Branco - Porto Alegre - Rio Grande do Sul/Brasil.

CEP: 90620-110 